\title{
Optical coherence tomography image in gelatinous drop-like corneal dystrophy: case report
}

\author{
Tomografia de coerência óptica na distrofia corneana gelatinosa em gotas: relato de caso \\ Otávio de Azevedo Magalhães ${ }^{1}$, Samuel Rymer², Diane Ruschel Marinho², Sérgio Kwitko², Isabel Habeyche Cardoso³ ${ }^{3}$ Lúcia Kliemann ${ }^{4}$
}

\begin{abstract}
Gelatinous drop-like corneal dystrophy is a rare disorder with few cases described in the present literature. The following report will show how difficult it is to diagnose this disease in early stages. Modern image exams, such as optical coherence tomography helps to diagnose and can be crucial to establish the best treatment. We will present the histopathological changes and clinical features in this unusual dystrophy.
\end{abstract}

Keywords: Corneal dystrophies, hereditary/diagnosis; Tomography, optical coherence/methods; Corneal opacity; Case report; Humans; Child

\section{RESUMO}

A distrofia corneana gelatinosa em gotas é uma desordem rara e pouco descrita em nossa literatura. O caso apresentado demonstra a dificuldade de realizaro diagnóstico nas fases mais iniciais da doença. O uso de modernos exames de imagem, como a tomografia de coerência óptica de segmento anterior, auxilia no diagnóstico e pode ser crucial para definir a melhor conduta terapêutica. Apresentaremos as alterações histopatológicas e as características clínicas desta incomum distrofia.

Descritores: Distrofias hereditárias da córnea/diagnóstico; Tomografia de coerência óptica/métodos; Opacidade da córnea; Relato de caso; Humanos; Criança

\section{INTRODUCTION}

Gelatinous drop-like corneal dystrophy is a rare disorder also known as primary familial amyloidosis of the cornea ${ }^{(1)}$. It usually occurs in the first decade of life and its clinical appearance can simulate other diseases such as band keratopathy ${ }^{(2)}$. Symptoms include photophobia, tearing and poor vision. Bilateral corneal opacification increases with age. Microscopic findings include subepithelial deposits that resemble a mulberry shape without any inflammatory component. The genetic inheritance pattern is not well established (3), but it is believed to be autosomal recessive. Bowman's membrane can be absent at the histopathological analysis and characteristic apple-green birefringence is viewed in polarized light ${ }^{(4)}$.

\section{CASE REPORT}

A five-year-old girl was referred to our Cornea and External Disease Department because of bilateral corneal opacity and low vision. Her past medical history was negative for any systemic disease, trauma or prenatal disorders. Similar findings were found in her 8-year-old brother, who had the same biomicroscopic characteristic but milder symptoms. Her best corrected visual acuity was counting fingers at 1 meter in both eyes. Slit lamp examination revealed a total lack of transparency, epithelial edema with bubbles and a thin layer of cal- cification (Figure 1). The main initial diagnostic hypothesis was congenital hereditary endothelial dystrophy (CHED) and a penetrating keratoplasty (PK) was indicated in the right eye. Histopathological analysis revealed amyloid nodules in the subepithelial layer and in the anterior portion of the corneal stroma that stained with Congo Red (Figure 2) and formed apple-green birefringence when combined with polarized light (Figure 3). Bowman's membrane was absent, there was no significant posterior stromal edema and Descemet's membrane was normal. Histopathological findings were consistent with the diagnosis of gelatinous drop-like corneal dystrophy and showed that our first hypothesis of CHED was mistaken. Optical Coherence Tomography (OCT - Optovue Fourier-Domain System ${ }^{\circledR}$ ) was performed in the opposite eye that had the same clinical appearance. This exam showed increased anterior reflectivity with nodules measuring about 327 microns in thickness. Total central corneal width was 1070 microns. There were no significant changes in the posterior stroma and Descemet's membrane (Figure 4).

\section{DISCUSSION}

There are few descriptions of this type of dystrophy and no reports of anterior OCT images. Had we performed a corneal OCT exam before PK of the right eye, we could have made a different surgical approach since the OCT showed only anterior stromal alterations.

Submitted for publication: June 12, 2012

Accepted for publication: July 27, 2012

Study carried out at the Hospital de Clínicas de Porto Alegre, Universidade Federal do Rio Grande do Sul.

Physician, Setor de Córnea e Doenças Externas, Serviço de Oftalmologia, Hospital de Clínicas de Porto Alegre, Universidade Federal do Rio Grande do Sul - UFRS - Porto Alegre (RS), Brasil.

2 Physician, Serviço de Oftalmologia, Hospital de Clínicas de Porto Alegre, Universidade Federal do

Rio Grande do Sul - UFRS - Porto Alegre (RS), Brasil.

Physician, Porto Alegre (RS), Brasil.

Physician, Serviço de Patologia, Hospital de Clínicas de Porto Alegre, Universidade Federal do Rio

Grande do Sul - UFRS - Porto Alegre (RS), Brasil.

Funding: No specific financial support was available for this study.

Disclosure of potential conflicts of interest: O.A.Magalhães, employee of Hospital Nossa Senhora da Conceição; S.Rymer, None; D.R.Marinho, employee of Hospital de Clínicas de Porto Alegre; S.Kwitko, None; I.H.Cardoso, None; L.Kliemann,

Correspondence address: Otávio de Azevedo Magalhães. Rua Mostardeiro, 333/401 - Porto Alegre (RS) - 90430-001 - Brazil - E-mail: otaviomaga@yahoo.com.br 


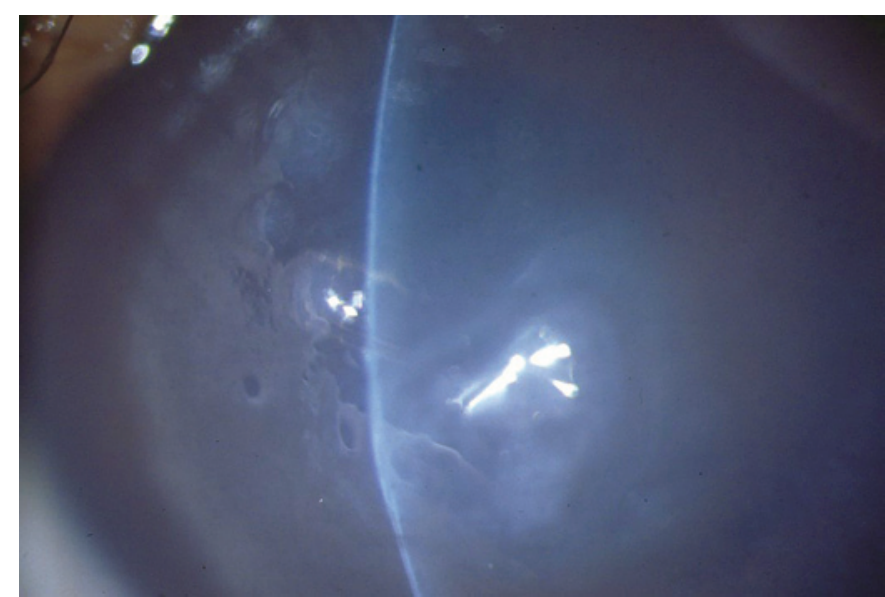

Figure 1.Gelatinous drop-like dystrophy biomicroscopic findings-grayish, mulberry-like and protruding subepithelial deposits.

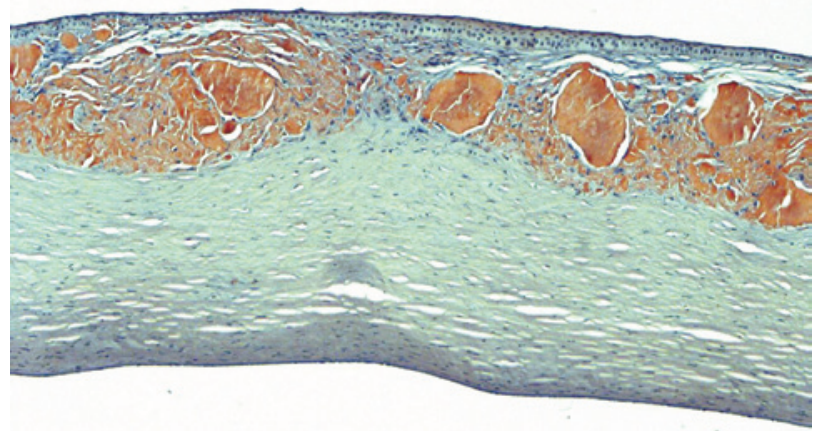

Figure 2. Red Congo stain showing anterior amyloid nodular deposits.

During the diagnostic investigation, it is essential to use this kind of technology. That way, invasive procedures with high rates of rejection can be avoided. Anterior lamellar procedures or phototherapeutic keratectomy $(\mathrm{PTK})^{(5)}$ can be better options for this disease.

\section{REFERENCES}

1. Nakaizumi K. A rare case of corneal distrophy. Acta Soc Ophthal Jpn. 1914;18:949-50.

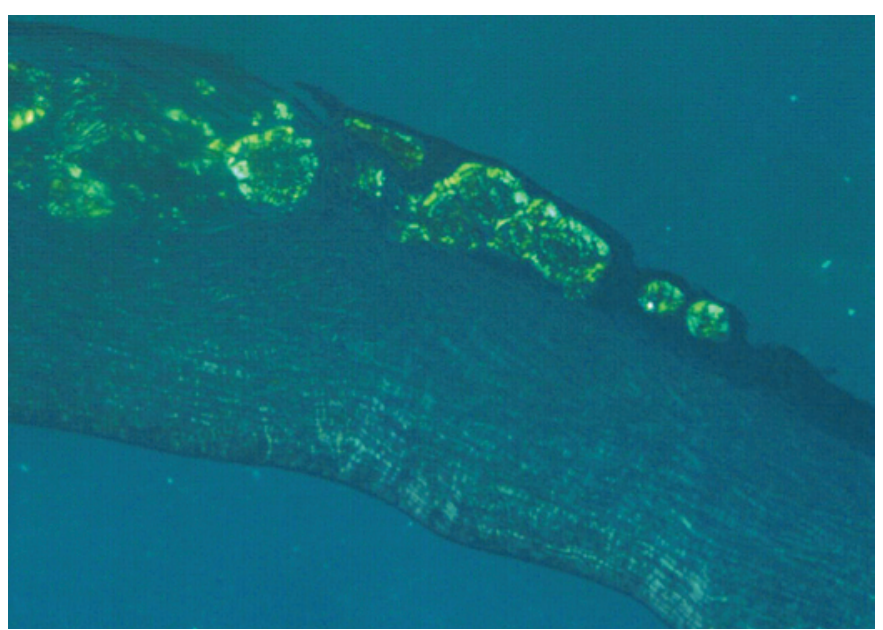

Figure 3. Apple-green birefringence when viewed with polarized light.

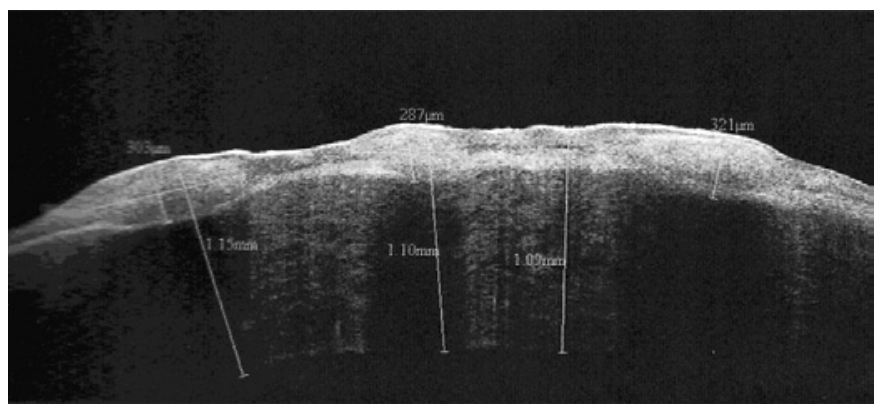

Figure 4. OCT image showing hypereflective nodular formation in the anterior corneal layer.

2. Kanai A, Kaufman HE. Electron microscopic studies of primary band-shaped keratopathy and gelatinous drop-like corneal dystrophy in two brothers. Ann Ophthalmol. 1982;14(6):535-9.

3. Kawasaki S, Kinoshita S. Clinical and basic aspects of gelatinous drop-like corneal dystrophy. Dev Ophthalmol. 2011;48:97-115.

4. Garner A. Amyloidosis of the cornea. Br J Ophthalmol. 1969;53(2):73-81.

5. Ito M, Takahashi J, Sakimoto T, Sawa M. [Histological study of gelatinous drop-like dystrophy following excimer laser phototherapeutic keratectomy]. Nihon Ganka Gakkai Zasshi. 2000;104(1):44-50. Japanese. 